\title{
Lice Becker-Ho, La part maudite dans l'œuvre de François Villon
}

\section{Paola Cifarelli}

\section{(2) OpenEdition}

10 Journals

\section{Édition électronique}

URL : https://journals.openedition.org/studifrancesi/20952

DOI : 10.4000/studifrancesi.20952

ISSN : 2427-5856

Éditeur

Rosenberg \& Sellier

\section{Édition imprimée}

Date de publication : 1 décembre 2019

Pagination : 556

ISSN : 0039-2944

\section{Référence électronique}

Paola Cifarelli, «Lice Becker-Ho, La part maudite dans l'œuvre de François Villon », Studi Francesi [En ligne], 189 (LXIII | III) | 2019, mis en ligne le 01 mars 2020, consulté le 12 novembre 2021. URL : http:// journals.openedition.org/studifrancesi/20952 ; DOI : https://doi.org/10.4000/studifrancesi.20952

Ce document a été généré automatiquement le 12 novembre 2021.

\section{(c) (i) (9)}

Studi Francesi è distribuita con Licenza Creative Commons Attribuzione - Non commerciale - Non opere derivate 4.0 Internazionale. 


\title{
Lice Becker-Ho, La part maudite dans l'œuvre de François Villon
}

\author{
Paola Cifarelli
}

\section{RÉFÉRENCE}

Lice Becker-Ho, La part maudite dans l'œuvre de François Villon, Paris, L'Echappée, 2018, $103 \mathrm{pp}$.

1 Les ballades en jargon de François Villon restent l'une des parties les plus hermétiques de l'œuvre du poète, malgré l'apport que les études de Lazare Sainéan, Louis Thuasne, Pierre Guiraud ou David Kuhn ont fourni au fil du temps pour leur décodage. A. B-H., essayiste qui a consacré plusieurs études à l'argot, mais surtout poète, se propose de traduire en un français moderne teinté d'argot les six ballades attribuées avec certitude à celui que Clément Marot, dans son édition de 1533, définissait comme le pionnier d'une poésie légère et satirique.

2 En faisant la part belle aux critiques que ces textes, considérés ici comme des "conseils que Villon prodigue sous une forme inédite à tous ses compagnons de mauvaise vie» (p.10), ont suscitées de tous temps, et en prenant les distances de la lecture proposée autrefois par P. Guiraud, l'A. ne prétend pourtant pas dévoiler tous les mystères que pose l'interprétation de ce code linguistique destiné à dissimuler et à égarer le profane; elle entend néanmoins éviter les solutions faciles adoptées parfois par les traducteurs qui l'ont précédée.

3 Après une évocation rapide de la biographie du poète telle qu'elle a pu être reconstruite sur la base des recherches menées jusqu'ici, ainsi que du contexte dans lequel il aurait composé ses vers, l'attention se focalise sur les questions concernant le rapport entre le jargon des ballades et l'argot; l'accent est mis tout particulièrement sur la contribution fournie par les recherches de Marcel Schwob, lui aussi écrivain passionné d'argot, qui étudia les actes du procès célébré à Dijon en 1455 contre les Coquillards et en tira un lexique alphabétique de leur langage, jugé une «véritable pierre de Rosette» (p.32) 
pour le décodage de ce dernier. Une étude vers par vers de la ballade I (Aparouart la grant mathegaudie), dans laquelle les termes argotiques font l'objet d'un commentaire spécifique, est suivie du texte des cinq autres poèmes, reproduit en fac-similé d'après la première édition gothique (Paris, Pierre Levet, 1489), accompagné d'une transcription diplomatique et ensuite traduit en français moderne avec des traits d'argot. Le lecteur familier avec le moyen français aura quelques difficultés à tirer profit de ce travail, conçu comme un exercice de style plutôt que comme une véritable étude scientifique rendant compte de tous les passages problématiques. La décision de ne pas intervenir sur la transcription pour ce qui est de la séparation des mots, des graphies à valeur multiple ou de l'accentuation (quelques exemples: a la sault = a l'asault, ballade II, str. 3, v. 3; enteruer = enterver, ballade IV, str. 1, v. 2; quacolles = qu'acollés, ballade $\mathrm{V}$, str. 1, v. 4) ne facilitera pas non plus la tâche au public des non spécialistes, auquel l'ouvrage s'adresse aussi; en effet, ce volume se rapproche souvent de l'essai car, bien que la documentation soit toujours solide et l'argumentation rigoureusement fondée, on n'y trouvera pas tous les traits caractérisant les travaux universitaires. Il n'en reste pas moins qu'il s'agit d'une lecture stimulante et d'une défense efficace de la valeur poétique de ces textes villoniens. 